\title{
PENGEMBANGAN DESAIN MODEL DAN PROTOTIPE MESIN SIKAT KARPET MEKANIK DENGAN PENGGERAK MOTOR LISTRIK
}

\author{
Bambang Setiawan ${ }^{1}$, Gunawan Hidayat ${ }^{2}$, Riki Effendi ${ }^{3}$ \\ Jurusan Teknik Mesin, Fakultas Teknik, Universitas Muhammadiyah Jakarta \\ Jl. Cempaka Putih Tengah No. 27, Jakarta Pusat, Indonesia \\ Email: bambangsetiawan1000@gmail.com¹,gunawan.hidayat@gmail.com² \\ riki.effendi@ftumj.ac.id ${ }^{3}$
}

\begin{abstract}
Abstrak
Desain mesin sikat karpet mekanik ini merupakan salah satu upaya pengembangan pada alat konvensional. Hal ini untuk membantu industri kecil yang masih menggunakan alat konvensional untuk beralih ke mesin sikat karpet mekanik agar dapat menghasilkan produk yang lebih cepat dan efektif pada saat proses mencuci karpet. Tujuan penelitian ini adalah untuk pengembangan desain model dan prototipe mesin sikat karpet mekanik dengan penggerak motor listrik, skala pencucian karpet rumah tangga. Tujuan pembuatan konsep ini meningkatkan efektivitas waktu untuk penggunanya. Alat ini digunakan untuk mencuci dan menyikat pada karpet, dimana alat tersebut bekerja menggunakan sumber daya dari motor listrik yang menggerakkan poros dan sikat pembersih/polisher untuk mencuci dan menyikat karpet yang sudah diberi cairan deterjen sebelumnya. Konsep perancangan alat sikat karpet mekanik ini dibuat dengan menggunakan Computer Aided Design (CAD) SOLIDWORKS. Metode yang dipakai untuk membuat mesin sikat karpet mekanik meliputi pengembangan model yang ada, mencari riset tentang alat sebelumnya, penyempurnaan konsep model desain, pembuatan model 3D dan pembuatan alat. Setelah alat selesai dirakit maka alat akan dites dan diuji. Pengujian mesin sikat karpet mekanik dengan menggunakan tiga jenis tipe karpet berdasarkan ketebalan bahan. Karakteristik karpet berpengaruh terhadap kinerja dari mesin serta hasil yang didapatkan.
\end{abstract}

Kata Kunci: Desain, Prototipe, Mesin sikat karpet mekanik.

\section{PENDAHULUAN}

Mesin sikat karpet mekanik merupakan mesin yang digunakan untuk membantu atau menyelesaikan sebuah pekerjaan di dalam industri terutama di bidang jasa khususnya loundry. Karena fungsi dari mesin sikat karpet mekanik ini ialah membersihkan debu dan kotoran yang menempel pada karpet itu sendiri. Di era moderen seperti ini mesin sikat karpet sudah ditemukan atau dibuat sebelumnya, namun di dalam pembuatan mesin sikat karpet sebelumnya masih banyak ditemukan kekurangan atau kelemahan yang mengakibatkan kinerja mesin tersebut masih lemah dan belum sesuai seperti yang diharapkan, contoh permasalahannya seperti desain yang kurang pas, kinerja mesin yang kurang maksimal, dan pengopersian yang kurang nyaman. Penelitian ini membuat dan mendesain ulang mesin sikat karpet yang sudah ada sebelumnya.

Alasan mengapa membuat mesin sikat karpet mekanik ini adalah:

1. Membantu pekerjaan seseorang agar lebih mudah dan cepat dalam proses mencuci karpet,

2. Alat yang sudah ada sebelumnya masih memiliki banyak kekurangan sehingga perlu dibutuhkan perancangan dan perhitungan ulang agar mesin sikat karpet menjadi lebih baik dari yang sudah ada sebelumnya.

Penelitian ini merencanakan dan membuat serta menguji mesin sikat karpet mekanik. 


\section{TINJAUAN PUSTAKA}

\section{Konsep Dasar Mesin Sikat Karpet}

Pada dasarnya mesin sikat karpet mekanik penggerak utamanya menggunakan motor listrik dengan tujuan menghasilkan gerak putar yang nantinya akan diteruskan melalui pully, sabuk, dan poros untuk menggerakkan sikat pembersih. Prinsip kerja mesin sikat karpet mekanik ini mirip atau menyerupai mesin pembersih lantai dan mesin polishing bodi mobil, dari ketiga mesin ini perbedaan yang sangat signifikan yaitu pengaplikasian dan pengoperasian yang berbeda serta desain dan beberapa komponen yang berbeda pula. Adapun kesamaan pada ketiga mesin tersebut adalah pada prinsip kerja mesinnya saja.

\section{Desain alat sebelumnya}

Mesin sikat karpet ini sebelumnya sudah ada yang membuatnya, namun dalam pendesainan dan perakitan alat yang sebelumnya masih terdapat banyak kekurangan sehingga perlu untuk dikembangkan dan diperbarui kembali. Penelitian ini mengembangkan dan merakit kembali mesin sikat karpet dengan desain dan perhitungan yang berbeda sehingga akan didapat hasil yang lebih maksimal dari mesin sikat karpet sebelumnya.

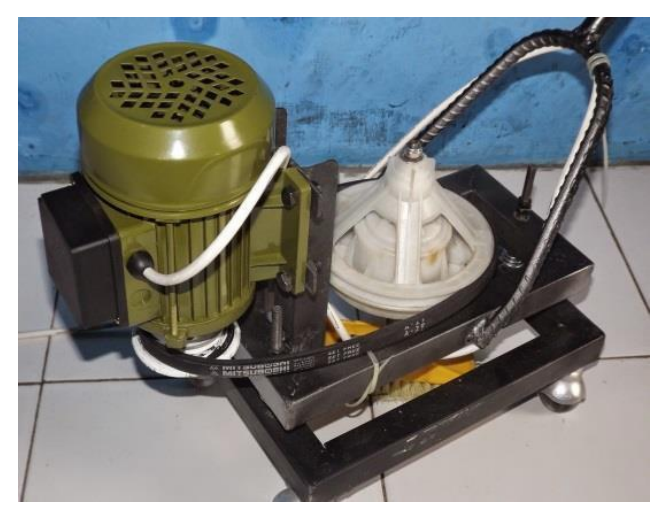

Gambar 1. Mesin sikat karpet sebelumnya [1].

\section{Karpet}

Karpet merupakan spesimen benda uji yang akan digunakan pada mesin sikat karpet mekanik ini. Dimana bagian karpet yang akan dijadikan spesimen pengujian adalah bagian permukaannya yang kotor yang akan dibersihkan menggunakan mesin sikat karpet ini. Karpet yang kotor akan menjadi bersih dan bahkan akan lebih bersih dari pada menggunakan sikat manual namun dengan tenaga yang dikeluarkan lebih sedikit sehingga hasilnya lebih efektif.

\section{Dasar-dasar dalam pemilihan bahan [2]}

Bahan yang merupakan syarat utama sebelum melakukan perhitungan komponen pada setiap perencanaan pada suatu mesin atau peralatan. Harus dipertimbangkan terlebih dahulu pemilihan mesin atau peralatan lainnya. Selain itu pemilihan bahan juga harus selalu sesuai dengan kemampuannya. Jenis-jenis bahan dan sifat-sifat bahan yang akan digunakan, misalnya tahan terhadap keausan, korosi dan sebagainya.

Adapun hai-hal penting yang diperhatikan dalam pemilihan bahan untuk komponen- komponen alat ini adalah:

a. Bahan yang digunakan sesuai dengan fungsinya.

Dalam pemilihan bahan, bentuk, fungsi dan syarat dari bagian alat bantu sangat perlu diperhatikan. Untuk perancangan harus mempunyai pengetahuan yang memadai tentang sifat mekanik, kimia, termal untuk mesin seperti baja besi cor, logam bukan besi (non ferro) dan sebagainya. Hal-hal tersebut berhubungan erat dengan sifat material yang mempengaruhi keamanan dan ketahanan yang direncanakan.

b. Bahan mudah ditemukan.

Yang dimaksud bahan mudah didapat adalah bagaimana usaha agar bahan yang dipilih untuk membuat komponen yang direncanakan itu selain memenuhi syarat juga harus mudah didapat dipasaran. Pada proses pembuatan alat terkadang mempunyai kendala pada saat menemukan bahan yang harus digunakan. Maka dari itu, bahan yang akan digunakan harus mudah ditemukan di pasaran agar tidak menghambat pada saat proses 
pembuatan.

c. Efektif dalam perencanaan dan pemakaian.

Dalam rancang bangun ini harus diperhatikan bahan yang seefektif mungkin. Dimana hal ini tidak mengurangi fungsi dari komponenkomponen tersebut sehingga material yang digunakan tidak terbuang dengan percuma.

d. Sifat teknik bahan.

Untuk mengetahiui bahan yang akan digunakan dapat dikerjakan mengunakan proses permesinan atau tidak. Kita perlu mengetahui sifat teknis bahan tersebut.

\section{Kriteria Pemilihan Komponen [3]}

Sebelum memulai perhitungan, seorang perencana haruslah terlebih dahulu memilih dan menentukan jenis material yang akan digunakan dengan tidak terlepas dari factor-faktor yang mendukungnya. Selanjutnya untuk memilih bahan nantinya akan didapatkan pada perhitungan, yaitu apakah komponen tersebut dapat menahan gaya yang besar, gaya terhadap beban puntir, beban bengkok atau terhadap faktor tahanan tekanan. Juga terhadap faktor koreksi yang cepat atau lambat akan sesuai dengan kondisi dan situasi tempat, komponen tersebut digunakan.

\section{METODE PENELITIAN}

\section{Konsep Penelitian}

Hal yang peratama harus dilakukan untuk membuat sebuah mesin sikat karpet mekanik ialah membuat konsep mesin terlebih dahulu. Setelah desain sudah dibuat dan bahan sudah ditentukan, maka tahap selanjutnya merancang bangun sesuai dengan bentuk dan ukuran yang ada di dalam desain tersebut. Ada beberapa tahapan yang harus dilakukan dalam merancang mesin sikat karpet mekanik ini antara lain: membuat kerangka/frame dilanjutkan dengan membuat poros, dan komponen-komponen lainnya dan perhitungan manual seperti rasio pully satu ke pully dua dan kapasitas daya mesin sikat karpet mekanik.

\section{Sistem transmisi [4]}

Sistem tranmisi pada mesin sikat karpet mekanik ini menggunakan sistem pully dan sabuk (belt). Penggunaan sistem ini dipilih karena lebih efektif dibanding menggunakan sistem tranmisi yang lain.

\section{Analisa Data}

Setelah proses rancang bangun mesin sikat karpet mekanik selesai maka langkah selajutnya ialah uji fungsional dengan menghidupkan mesin sikat karpet mekanik dan setelah itu dilakukan lah uji kinerja.

\section{Uji kenerja}

Uji kinerja dari mesin sikat karpet mekanik ini berlangsung selama satu hari yaitu dengan menguji terhadap karpet yang akan dijadikan spesimen benda uji. Pada pengujian alat ini spesimen benda uji yang di gunakan ada tiga jenis karpet yaitu karpet tipis, karpet sedang, dan karpet tebal. Jika dalam pengujian alat ini berhasil dengan maksimal maka sampai disinilah alat selesai dibuat. Tapi jika dalam pengujian alat ini mendapati masalah maka hal selanjutnya akan dicari dan dianalisa kembali bagian mana yang terdapat masalah pada mesin sikat karpet mekanik ini.

\section{Metode pengujian}

Metode yang dipakai dalam pengujian mesin sikat karpet mekanik ini menggunakan variasi jenis karpet. Jadi pengujian ini adalah untuk membandingkan antara sikat manual dengan mesin sikat karpet mekanik, manakah yang akan lebih efektif dari segi efektif waktu dan efektif tenaga.

\section{Spesimen Uji} benda uji:
Berikut adalah gambar spesimen 


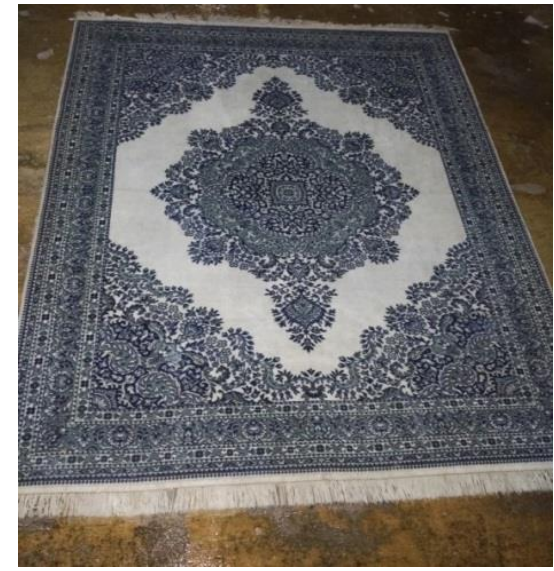

Gambar 2. Spesimen benda uji I

Pada gambar 2 di atas adalah karpet untuk spesimen benda uji dengan ukuran $200 \times 140 \mathrm{~cm}$ dan tebal $3 \mathrm{~mm}$.

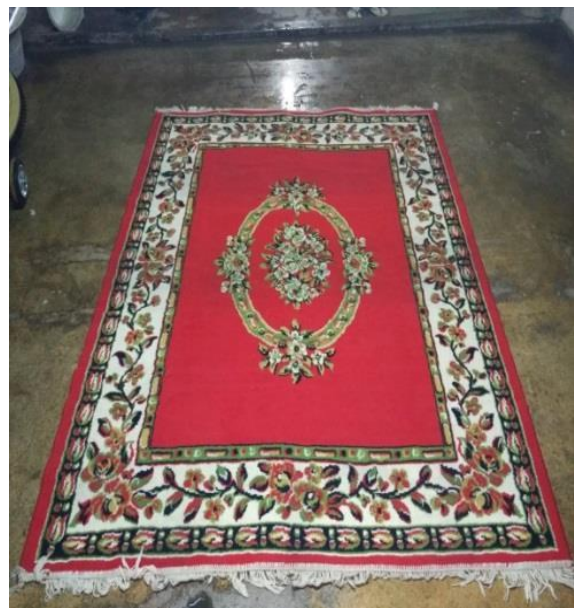

Gambar 3. Spesimen benda uji II

Pada gambar 3 di atas adalah karpet untuk spesimen benda uji dengan ukuran 200 x $160 \mathrm{~cm}$ dan tebal $6 \mathrm{~mm}$.

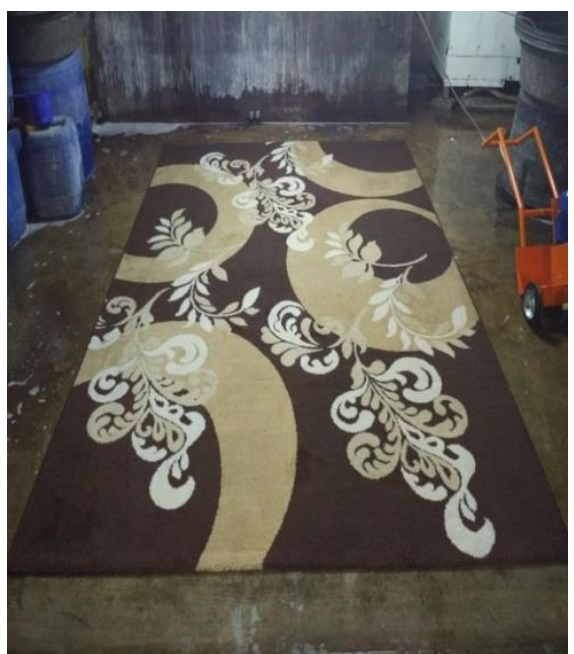

Gambar 4. Spesimen benda uji III
Pada gambar 3 di atas adalah karpet untuk spesimen benda uji dengan ukuran 310 x $210 \mathrm{~cm}$ dan tebal $10 \mathrm{~mm}$.

\section{Diagram Alir Penelitian}

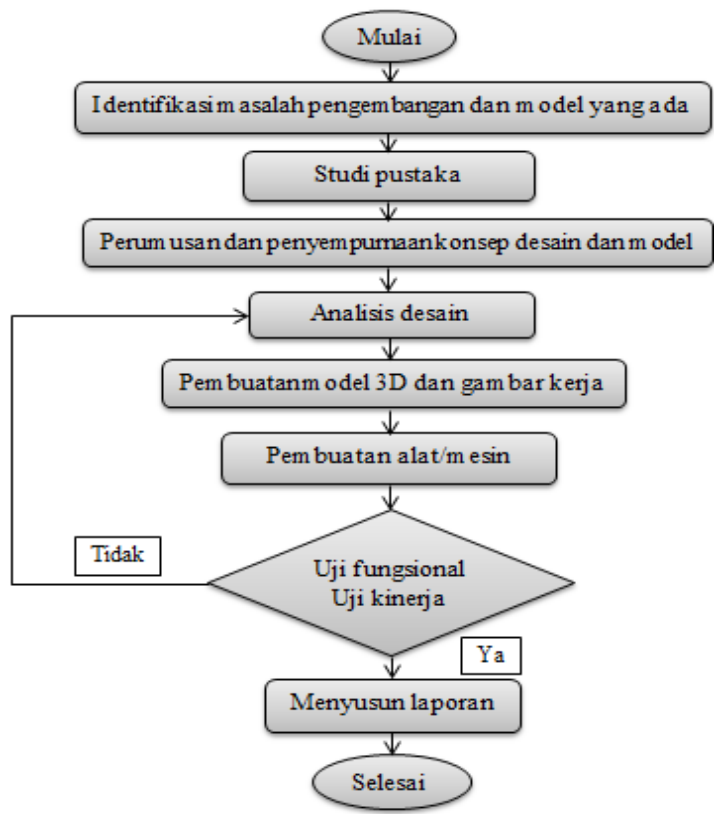

Gambar 5. Diagram Alir Penelitian

\section{HASIL DAN PEMBAHASAN}

\section{Desain Model}

Hal pertama yang dilakukan dalam membuat alat adalah membuat desain kerangka awal. Hal ini sangat penting sekali karena akan ditentukannya ukuran komponen lainnya yang akan digunakan pada mesin sikat karpet mekanik.

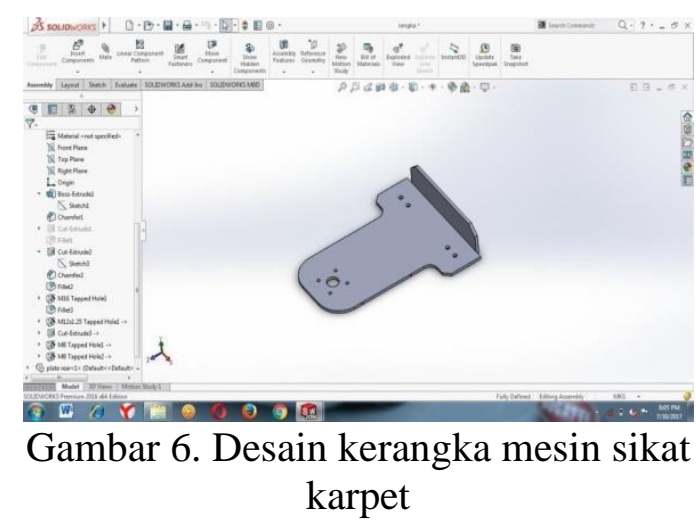

Pada gambar 6 di atas adalah desain kerangka awal mesin sikat karpet mekanik. Pada tahapan ini kerangka mesin dibentuk dan diukur sesuai apa yang direncanakan. Selanjutnya adalah mendesain dudukan (base motor). Pada tahapan ini dudukan 
disesuaikan dengan kerangka mesin yang nantinya akan digunakan untuk penempatan motor listrik, terlihat seperti pada gambar 7 berikut.

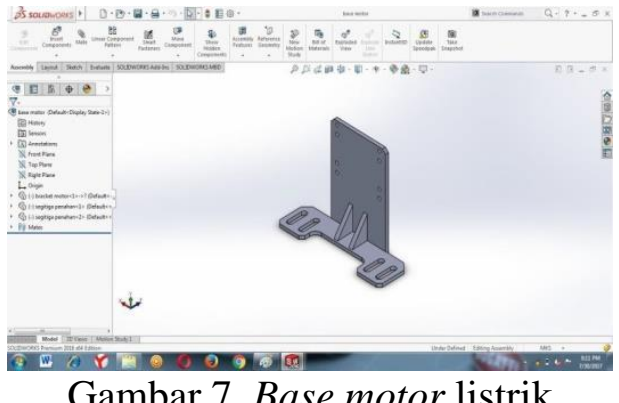

Gambar 7. Base motor listrik

Selanjutnya mendesain cover atau pengaman pully. Pada tahapan ini cover disesuaikan ukuranya dengan diameter pully yang akan digunakan dan ukur ketinggiannya agar nantinya cover tidak mentok atau menempel pada pully.

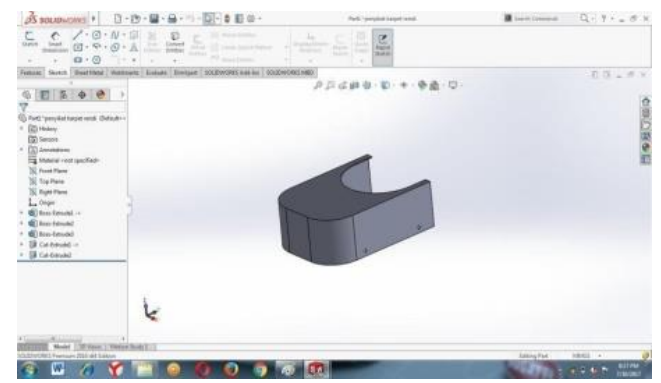

Gambar 8. Cover pully

Selanjutnya adalah mendesain poros pada mesin sikat karpet mekanik. Pada tahapan ini poros didesain sedemikian rupa agar sesuai dengan apa yang direncanakan. Pada alat ini poros digunakan untuk penerus daya dari motor listrik ke sikat polisher. Poros yang di pakai ada 2 jenis yaitu yang pertama poros penerus daya motor listrik dan yang ke dua poros as untuk pempatan roda pada mesin sikat karpet.

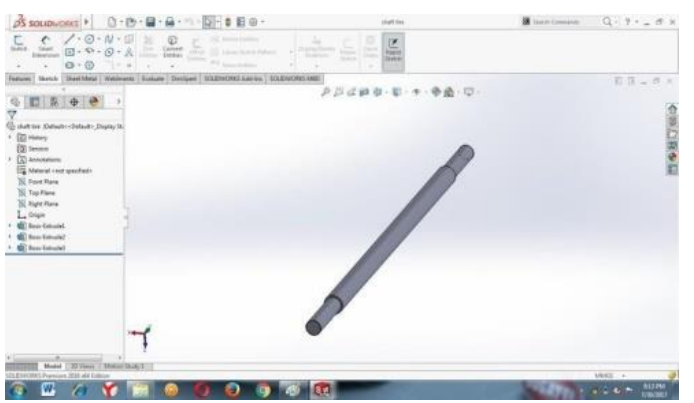

Gambar 9. Desain poros
Selanjutnya desain bantalan, pada alat ini bantalan digunakan untuk menumpu poros beban sekaligus untuk mengurangi gesekan antara poros dan rumahnya sehingga menjadikan poros dan rumahnya tidak aus karena tidak bergesekan secara langsung tapi melalui bearing. Pada mesin sikat karpet bantalan yang digunakan adalah pillow blok, bantalan ini memiliki lubang baut pada ke empat sisinya sehingga akan lebih kuat untuk menahan beban yang di timbulkan oleh mesin sikat karpet.

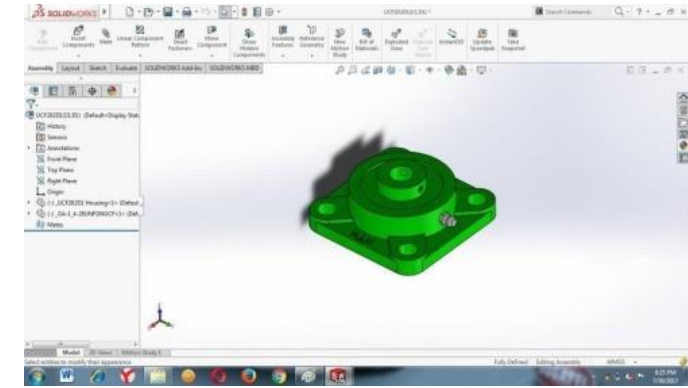

Gambara 10. Desain pillow blok

Selanjutnya desain pully pada mesin sikat karpet. Pada tahapan ini pully didesan sedemikian rupa dan diukur sesuai dengan apa yang sudah di rencanakan. Pully yang digunakan pada mesin sikat karpet ini memiliki ukuran 6 inchi dengan tipe sabuk A. Fungsi dari pully ini adalah untuk meneruskan daya dari motor listrik ke poros mesin sikat karpet.



Gambar 11. Desain pully mesin sikat karpet

Tahap selanjutnya adalah desain sikat polisher. Pada mesin sikat karpet ini sikat polisher merupakan komponen utama dan paling penting karena sebelum dirancangnya mesin sikat karpet perlu diketahui terlebih dahulu ukuran diameter 
sikat polisher yang akan digunakan dan selanjutnya baru di buatkan desain mesin sikat karpet. Ukuran diameter polisher yang dipakai pada mesin sikat karpet ini adalah 17 inchi.

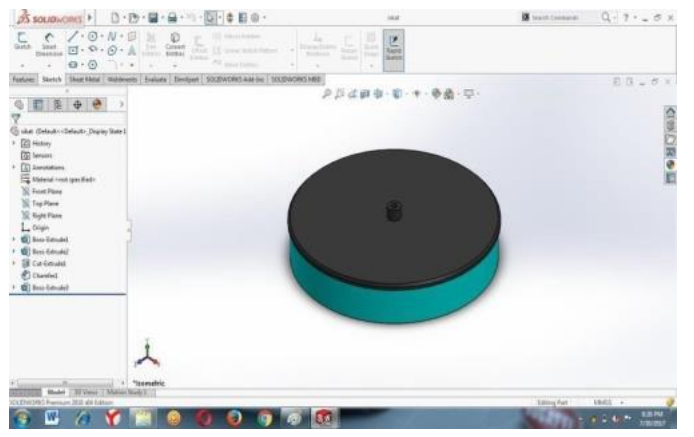

Gambar 12. Desain polisher

Tahap selanjutnya adalah desain motor listrik yang digunakan pada mesin sikat karpet. Motor listrik ini digunakan untuk menghasilkan daya yang nantinya akan transmisikan menuju poros lalu ke sikat polisher. Motor listrik yang dipakai pada mesin sikat karpet memiliki kapasitas daya $0,5 \mathrm{HP}$ dan putaran $1330 \mathrm{rpm}$.

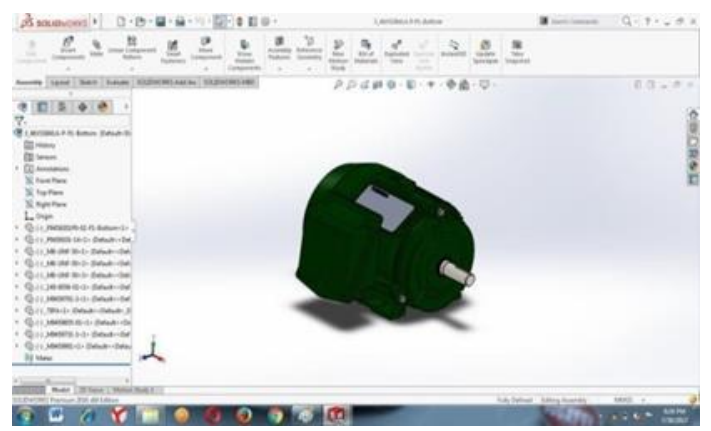

Gambar 13. Desain motor listrik

Tahap selanjutnya adalah desain pully untuk motor listrik. Pada tahapan ini pully yang dipasangkan pada motor listrik memiliki diameter ukuran 2 inchi. Pully ini digunakan untuk mentransmisikan daya yang nantinya akan menghasilkan gerak rotasi pada sikat polisher.

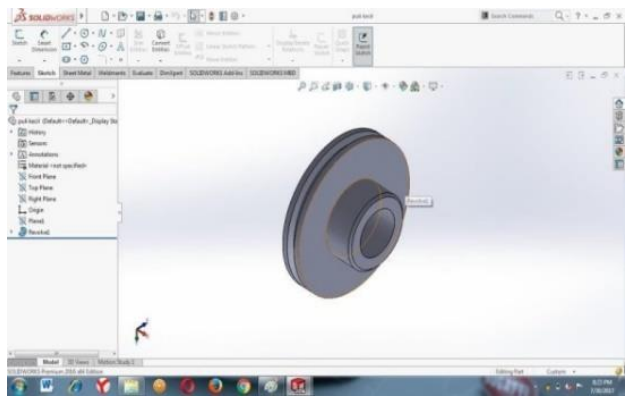

Gambar 14. Desain pully pada motor
Tahap selanjutnya adalah desain roda pada mesin sikat karpet. Pada tahapan ini roda didesain dengan diameter ukuran 6 inchi. Fungsi dari roda ini adalah untuk membantu atau roda pada mesin sikat karpet terlihat seperti pada gambar $15 \mathrm{di}$ bawah ini.

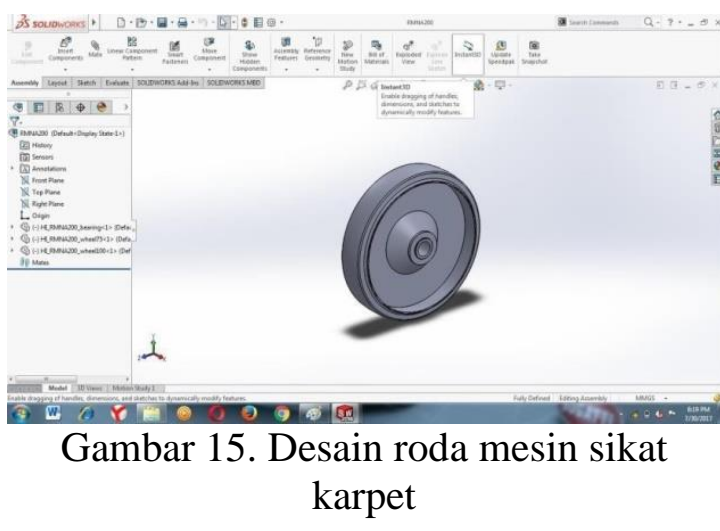

Tahapan yang terakhir adalah mendesain handel atau dorongan untuk mesin sikat karpet mekanik. Pada tahap ini handel didesain dengan tinggi $85 \mathrm{~cm}$ dan lebar $26 \mathrm{~cm}$. Fungsi dari handel ini adalah sebagai setir untuk mengatur arah gerak mesin pada saat dioperasikan.

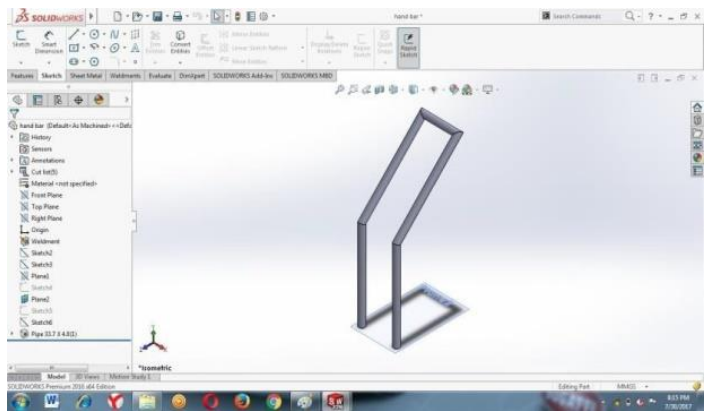

Gambar 16. Handel mesin sikat karpet mekanik

Setelah semua komponen selesai di buat maka tahap selanjutnya semua komponen di-assembly menjadi satu dan jadilah desain model mesin sikat karpet mekanik.

Gambar 17 adalah mesin sikat karpet yang sudah selesai dibuat. 


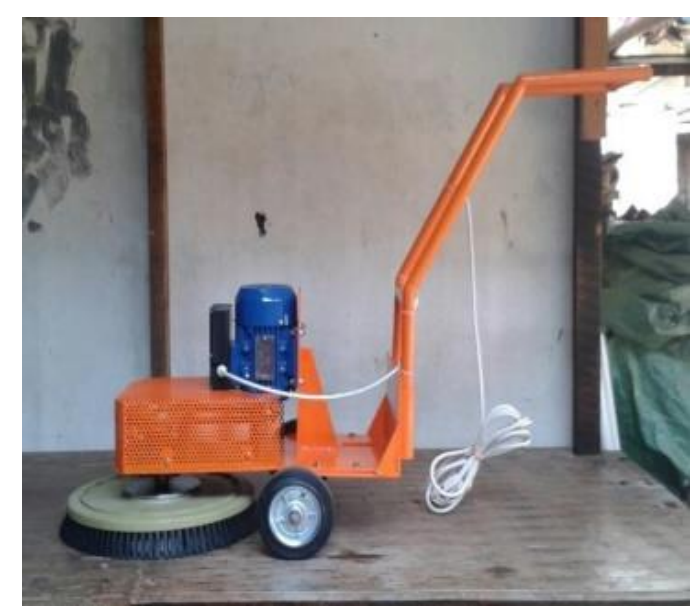

Gambar 17. Mesin sikat karpet mekanik

\section{Hasil Pengujian}

Berdasarkan hasil eksperimen pada mesin sikat karpet mekanik dengan membandingkan proses secara manual dan menggunakan alat untuk mencuci karpet dan juga memvariasikan jumlah karpet dalam berapa menit yaitu dengan 1 buah karpet tipis, 1 buah karpet sedang, dan 1 buah karpet tebal dengan ukuran yang berbeda-beda, maka didapatkan data eksperimen berupa waktu yang diperlukan dalam 3 buah karpet.

Tabel 1. Pengujian perbandingan dengan 1 kali pencucian.

\begin{tabular}{|c|c|c|c|}
\hline $\begin{array}{c}\text { Pengu } \\
\text { jian }\end{array}$ & Ukuran (cm) & $\begin{array}{c}\text { Konve } \\
\text { nsional } \\
(\mathrm{det})\end{array}$ & $\begin{array}{c}\text { Mesin } \\
(\mathrm{det})\end{array}$ \\
\hline 1 & $200 \times 140 \times 0,3$ & 200 & 165 \\
\hline 2 & $200 \times 160 \times 0,6$ & 210 & 97 \\
\hline 3 & $310 \times 210 \times 1$ & 250 & 159 \\
\hline
\end{tabular}

Dari tabel 1 di atas menunjukkan bahwa dari hasil proses menyikat karpet dengan menggunakan mesin, selisih waktu yang didapatkan lebih cepat dibandingkan menggunakan sikat manual.

Tabel 2. Pengujian perbandingan dengan 2 kali pencucian.

\begin{tabular}{|c|c|c|c|}
\hline $\begin{array}{c}\text { Peng } \\
\text { ujian }\end{array}$ & Ukuran $(\mathrm{cm})$ & $\begin{array}{c}\text { Konve } \\
\text { nsional } \\
(\text { det })\end{array}$ & $\begin{array}{c}\text { Mesin } \\
(\text { det })\end{array}$ \\
\hline 1 & $200 \times 140 \times 0,3$ & 130 & 102 \\
\hline 2 & $200 \times 160 \times 0,6$ & 139 & 68 \\
\hline 3 & $310 \times 210 \times 1$ & 220 & 116 \\
\hline
\end{tabular}

Dari tabel 2 di atas menunjukkan hasil yang diperoleh dari pengujian proses menyikat karpet yang ke dua kalinya dengan menggunakan mesin, didapatkan selisih waktu yang lebih cepat dibandingkan dengan pengujian yang pertama.

Tabel 3. Perbandingan dengan 3 kali pencucian.

\begin{tabular}{|c|c|c|c|}
\hline $\begin{array}{c}\text { Pengu } \\
\text { jian }\end{array}$ & Ukuran (cm) & $\begin{array}{c}\text { Konve } \\
\text { nsional } \\
\text { (det) }\end{array}$ & $\begin{array}{c}\text { Mesin } \\
\text { (det) }\end{array}$ \\
\hline 1 & $200 \times 140 \times 0,3$ & 86 & 65 \\
\hline 2 & $200 \times 160 \times 0,6$ & 94 & 49 \\
\hline 3 & $310 \times 210 \times 1$ & 149 & 98 \\
\hline
\end{tabular}

Dari tabel 3 di atas menujukkan hasil yang diperoleh dari pengujian proses menyikat karpet yang ke tiga kalinya dengan menggunakan mesin, selisih waktu yang didapatkan lebih cepat dibandingkan dari pengujian pertama dan kedua.

\section{KESIMPULAN}

Dari hasil pengujian pada tabel 1,2, dan 3, dapat disimpulkan bahwa proses menyikat karpet dengan menggunakan mesin jauh lebih cepat dibandingkan menggunakan sikat konvensional. Penggunaan mesin sikat karpet ini sangat efektif untuk mencuci atau menyikat karpet dengan ukuran dan ketebalan yang berbeda-beda.

\section{REFERENSI}

[1]. Paoji. 2015. Bisnis Mesin Sikat Karpet.jurnalpriangan.com/ 2015/09/09.

[2]. Sularso. 1978. Dasar Perencanaan Dan Pemilihan Bahan Elemen Mesin, Jakarta.

[3]. Khurmi, R.S dan J.K. Gupta. 1982. A Text Book Of Machine Design. Eurasia Publishing House (Pvt.) LTD Ram Nagar. New Delhi.

[4]. Sularso. 1991. Transmisi Sabuk Vbel. Jakarta. 